Lucia Chaves Blanco

Cristina Gómez-Camarasa

Marta Illescas López

Natalia Chueca Porcuna

Laura L. Rojas-García

\title{
Unusual isolation of Pseudoglutamicibacter cumminsii in urine culture
}

Microbiology Clinic Unit, Hospital Universitario San Cecilio. Granada, Spain.

Article history

Received: 12 June 2021; Revision Requested: 21 August 2021; Revision Received: 31 August 2021; Accepted: 2 September 2021; Published: 29 November 2021

\section{Sir,}

Pseudoglutamicibacter cumminsii is an aerobic, catalase-positive, Gram-positive coccobacillus commonly found in soil. Recently, a change has been made in the taxonomy of this species, which was previously classified as Arthrobacter cumminsii [1]. The literature associated with urinary tract infection (UTI) is rare [2,3], although other cases of infections caused by related species within this genus, such as bacteraemia caused by A. creatinolyticus [4] or endocarditis caused by A. woluwensis [5], have been reported.

A 34-year-old woman with no personal history of interest visited her primary care medical centre with persistent urinary symptoms. She was diagnosed with cystitis and was prescribed Fosfomycin $3 \mathrm{~g}$ oral solution, two doses. Two weeks later, she returned to the health centre reporting continued urinary symptoms, without episodes of fever.

The patient was asked to send a urine sample for culture in the microbiology laboratory. The sample was inoculated in CPSO chromogenic medium (Biomerieux ${ }^{\circledR}$, Marcy L'Etoile, France) and incubated for 24 hours in a $37^{\circ}$ atmosphere. After the incubation time, a pure culture count of $>100,000 \mathrm{CFU} / \mathrm{ml}$ of a yellowish colony was observed (Figure 1).

Identification of the microorganism was performed by mass spectrometry, MALDI-TOF (Bruker ${ }^{\circledR}$, Bremen, Germany). Pseudoglutamicibacter cumminsii was obtained with a score of 1.65. The identification was confirmed by using $16 \mathrm{~S}$ rRNA gene sequence (GenBank accession number: MZ293797). Antibiotic susceptibility was tested by disc diffusion and Corynebacterium cut-off points in EUCAST (European Committee on Antimicrobial Susceptibility Testing) 2021 were taken as a reference for antibiogram interpretation. The susceptibility profile reported was as follows: susceptible to imipenem,

Correspondencia:

Cristina Gómez Camarasa

Microbiology Clinic Unit, Hospital Universitario San Cecilio. Granada, Spain.

E-mail: gomezcamarasa@gmail.com

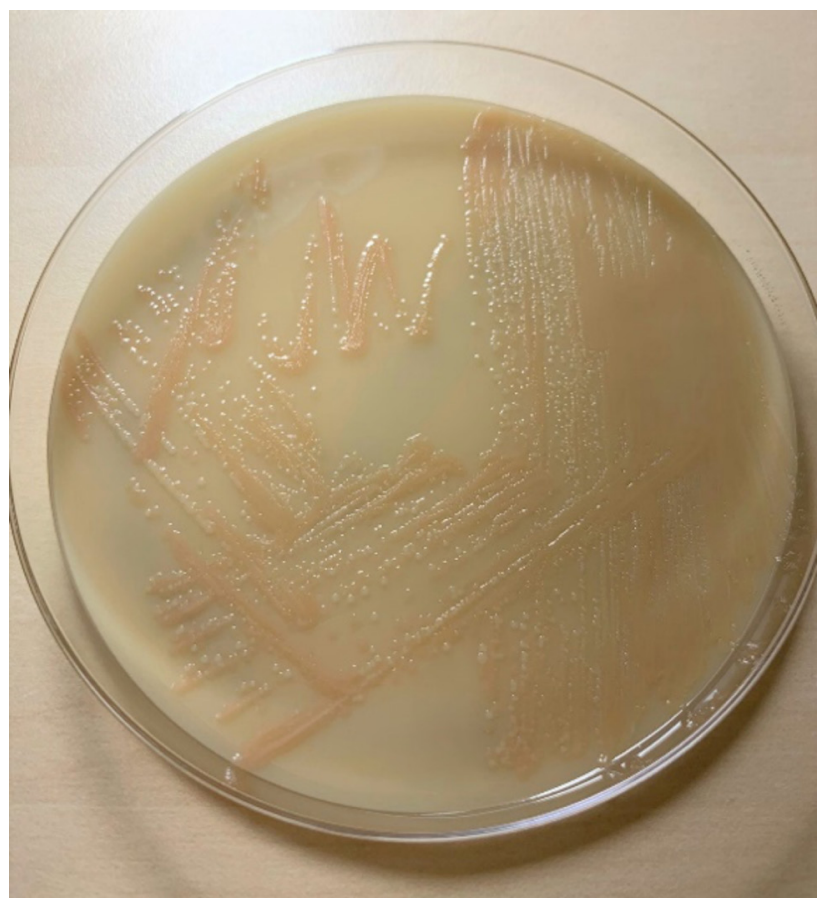

Figure $1 \quad$ Colonies of $P$. cumminsii grown in $\mathrm{CPSO}^{\circledR}$ chromogenic agar (Biomerieux ${ }^{\circledR}$ )

linezolid, rifampicin, tetracycline and vancomycin, and resistant to ciprofloxacin, clindamycin, erythromycin, gentamicin, levofloxacin and penicillin.

Subsequently, the patient was treated with doxycycline $100 \mathrm{mg}$ for 7 days with successful results. No new post-treatment control sample was sent.

Few reports have associated this microorganism to urinary tract infection $[2,3]$. However, the etiology of UTI's can be very wide ranging, from the most common pathogens such as Es- 
cherichia coli, Proteus mirabilis or Klebsiella pneumoniae, to other less frequent pathogens described in the literature [6]. Accurate identification methods and antibiotic susceptibility constitute a fundamental tool in the diagnosis of urinary tract infections caused by underdiagnosed emerging pathogens.

\section{FUNDING}

None to declare

\section{CONFLICTS OF INTEREST}

The authors declare no conflicts of interest.

\section{REFERENCES}

1. Busse H-J. Review of the taxonomy of the genus Arthrobacter, emendation of the genus Arthrobacter sensu lato, proposal to reclassify selected species of the genus Arthrobacter in the novel genera Glutamicibacter gen. nov., Paeniglutamicibacter gen. nov., Pseudoglutamicibacter gen. nov., Paenarthrobacter gen. nov. and Pseudarthrobacter gen. nov., and emended description of Arthrobacter roseus. Int. J. Syst. Evol. Microbiol 2016;66:9-37. doi: 10.1099/ijsem.0.000702.

2. Navarro D, Aguilera A, Manso T, Vallejo A, Garcia X, Trastoy R, et al. Infección urinaria por Artrhrobacter cumminsii. Complejo Hospitalario Universitario de Santiago de Compostela. Póster presentado en: XX Congreso de la Sociedad Española de Enfermedades Infecciosas y Microbiología Clínica (SEIMC), 26-28 de mayo de 2016, Barcelona.

3. Pearce MM, Hilt EE, Rosenfeld AB, Zilliox MJ, Thomas-White $K$, Fok $C$, et al. The Female Urinary Microbiome: a Comparison of Women with and without Urgency Urinary Incontinence. MBio 2014;5:e01283-14. doi: 10.1128/mBio.01283-14.

4. Yamamoto K, Hayakawa K, Nagamatsu M, Fujiya Y, Mawatari M,

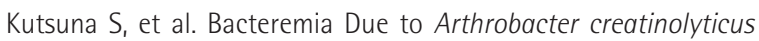
in an Elderly Diabetic Man with Acute Cholangitis. Jpn J Infect Dis 2017;70:201-2. doi: 10.7883/yoken.JJID.2016.033.

5. Durand C, Kouchit Y, Prots L, Degand N, Dellamonica P, Demonchy $E_{1}$ et al. A case of infective endocarditis caused by Arthrobacter woluwensis. Eur J Clin Microbiol Infect Dis 2021. doi: 10.7883/ yoken.JJID.2016.033.

6. Gómez-Camarasa C, Liébana-Martos C, Navarro-Marí JM, Gutiérrez-Fernández J. Detección de uropatógenos inusuales durante un periodo de 3 años en un hospital regional. Rev Esp Quimioter 2015; 28 (2): 86-91. PMID: 25904515. 